\title{
Perspectives
}

\section{Task-Based Language Teaching and Expansive Learning Theory}

\section{Margaret Robertson}

Task-Based Language Teaching (TBLT) has become increasingly recognized as an effective pedagogy, but its location in generalized sociocultural theories of learning has led to misunderstandings and criticism. The purpose of this article is to explain the congruence between TBLT and Expansive Learning Theory and the benefits of doing so. The merit of locating TBLT in Expansive Learning Theory is that it provides concrete explanations for how cycles of meaning making and negotiation can be worked into task phases. It provides an elaboration of the cyclical learning processes that may be embedded in tasks, improving the intentionality and focus of language tasks. In doing this it clearly establishes task-based teaching as a robust construct for language teaching programs. Additionally, the location of TBLT within Expansive Learning Theory makes explicit the central importance of intercultural communication competence to language learning, positioning culture as a mediating artefact in learning. This may provide teachers choosing to use TBLT as their pedagogy with a theoretical underpinning of expansive learning and with tools to assist their teaching practice. Additionally, it may contribute to teacher training and professional development through clarity provided by placing TBLT pedagogy within the theoretical framework of Expansive Learning Theory.

L'enseignement des langues basé sur les tâches (ELBT) est de plus en plus perçu comme une pédagogie efficace, mais sa place au sein des théories socioculturelles de l'apprentissage a donné lieu à des malentendus et des critiques. L'objectif de cet article est d'expliquer la concordance entre l'ELBT et la théorie de l'apprentissage expansif, d'une part, et les avantages de le faire, d'autre part. Le fait de situer l'ELBT dans la théorie de l'apprentissage expansif permet d'offrir des explications concrètes pour l'intégration des cycles de production de sens et de négociation dans les phases de tâches. L'élaboration des processus d'apprentissage cyclique qui peuvent être ancrés dans les tâches vient améliorer l'intentionnalité et l'objectif des tâches langagières, établissant ainsi l'enseignement basé sur les tâches comme cadre solide des programmes d'enseignement des langues, exposant l'importance centrale de la communication interculturelle dans l'apprentissage d'une langue et remettant à la culture un rôle de médiateur dans l'apprentissage. Tout ceci peut offrir aux enseignants qui choisissent de baser leur pédagogie sur l'ELBT un fondement théorique en apprentissage expansif et des outils pour appuyer leur 
pratique. L'intégration de la pédagogie de l'ELBT au sein du cadre théorique de l'apprentissage expansif peut également contribuer à la formation et au développement professionnel des enseignants.

Task-Based Language Teaching (TBLT) has become increasingly recognized as an effective pedagogy, but its location in generalized sociocultural theories of learning has led to misunderstandings and criticisms: it is claimed that the lack of controlling structure of tasks may lead to unpredictable outcomes, rendering TBLT appropriate only for experienced teachers with high target language proficiency; it has been viewed as unsuitable for exam preparation; and it allegedly does not sufficiently privilege the learning of grammar rules (Willis \& Willis, 2012). Expansive Learning Theory is a theoretical framework that lacks an explicit pedagogy, though it is implicitly taskbased. The purpose of this article is to explain the congruence between TBLT and Expansive Learning Theory and the benefits of doing so. This may provide teachers choosing to use TBLT as their pedagogy with a theoretical underpinning of expansive learning and with tools to assist their teaching practice. Additionally, it may contribute to teacher training and professional development through clarity provided by placing TBLT pedagogy within the theoretical framework of Expansive Learning Theory.

The article commences with a definition of pedagogy, the positioning of learning theory, and the central argument for the location of TBLT within Expansive Learning Theory as a specific subset of sociocultural theories of learning. This is followed by an analysis of key features of TBLT and congruent points with Expansive Learning Theory, including an elaboration of how understandings of learning in Expansive Learning Theory may be used to provide a framework for understanding TBLT pedagogy. The elements of the interacting activity systems of Expansive Learning Theory are then examined and the benefits of using these elements to strengthen task design and teaching practices highlighted. The final section argues that, by locating TBLT within Expansive Learning Theory, the positioning of intercultural communicative competence becomes explicit to TBLT.

\section{Theoretical Perspective}

Teaching practice is strengthened by an understanding of pedagogy, and pedagogy is strengthened by an understanding of the theoretical framework that underpins it. It has been my observation over many years as a teacher and school principal that the most effective teachers - those who are able to consistently cause or allow learners to acquire new knowledge (MacNeill \& Silcox, 2003) - have a clearly articulated framework of understanding that informs their teaching practices. Teachers who appreciate how and why their chosen pedagogy creates learning are more able to adapt and refine their 
practices to their teaching context. An understanding of pedagogy is cogently expressed by Alexander (2013) who argues that pedagogy is

the act of teaching together with its attendant discourse of educational theories, values, evidence and justifications. It is what one needs to know, and the skills one needs to command in order to make and justify the many different kinds of decisions of which teaching is constituted. (p. 47)

In this definition we see clearly the purpose of pedagogy as teaching, underpinned by theoretical understandings of learning, the values embedded in the translation of theory to practice, and evidence that supports and justifies this translation. From its early development TBLT has been located in sociocultural learning theories with the understanding that language learning required "the creation of conditions in which learners engage in an effort to cope with communication" (Prabhu, 1987, p. 1), and more specifically in Activity Theory (Ellis, 2003). The merit of locating TBLT in Expansive Learning theory is that it provides concrete explanations for how the Expansive Learning Theory cycles of meaning making and negotiation can be worked into task phases. Additionally, it provides an elaboration of the cyclical learning processes that may be embedded in tasks, improving the intentionality and focus of language tasks. In doing this it clearly establishes task-based teaching as a robust construct for language teaching programs.

TBLT is a pedagogy premised on the belief that "the most effective way to teach a language is by engaging learners in real language use" through teacherdesigned tasks that "require learners to use the language for themselves" (Willis \& Willis, 2012, p. 1). Because TBLT is an adaptive pedagogy, with teachers encouraged to refine their approach to task design to suit their context, the definition of this methodology relies heavily on a meaning-making, threephase cycle of pretask/task/posttask. Expansive Learning Theory builds on the concepts of learning on a cycle or spiral, commencing with questioning and moving through various stages to consolidation of new and transferable knowledge in a manner resonant with TBLT. It also positions intercultural knowledge as fundamental to language learning. Yet Expansive Learning Theory offers much more. Using the foundational conception of interactive Activity Systems, TBLT as pedagogy is elaborated. Within this elaboration, concerns about TBLT from critics (Bruton, 2002; Hampshire \& Aguareles Anoro, 2004; Seedhouse, Walsh, \& Jenks, 2010; Sheen, 2003; Swan, 2005) on a number of issues may be addressed.

\section{Learning Cycles or Spirals}

Expansive Learning Theory is a sociocultural theory of learning. Originally directed at learning in the workplace, and how learning at work produces new forms of work activity, this theory keeps a sharp focus on learning 
and systemic modification and adaptation. It is a theory of learning that demonstrates how and why prior knowledge is transformed through a cyclical sequence into new, internalized, and transferable knowledge. New and pre-existing knowledge is synthesized to create new knowledge that can lead to improvements and modifications of knowledge and social practice. Drawing on Bateson (2000), Engeström (2001) elaborates a hierarchy of learning. Learning I may be expressed as simple learning, the kind of learning that a young child experiences: If I cry, someone will comfort me. Learning II involves learning cultural patterns of behaviours, knowing the rules in a context, and understanding the expected sequences. This learning may lead to a double bind, "a situation in which no matter what a person does, they 'can't win'" (Bateson, 2000, p. 201). Typically a double bind is a situation where an individual (or group) receives conflicting cues; to follow one places you at risk of transgressing in the other. All existing options are likely to lead to an unsatisfactory outcome. This concept may have particular significance for this study in which foreign language learners, in attempting to learn new patterns of communication of an unfamiliar culture, may feel that all available language options are insufficient or inadequate. That is, old knowledge or taken-for-granted paradigms are no longer seen as adequate and therefore need to be modified. This experience may prompt Learning III, "a corrective change in the system of sets of alternatives from which choice is made" (Bateson, 2000, p. 293). This third type of learning occurs when "a person or a group begins to radically question the sense and meaning of the context and to construct a wider alternative context" (Engeström, 2001, p. 138). Effective task-based language teaching seeks to achieve the same outcome by shifting learners into new and expanded communication patterns.

Expansive learning may be understood as a cycle or spiral of learning that commences with questioning. The cycle then moves through a sequence of analysis: the double bind becomes apparent; the new solution or breakthrough is modelled; trial (examining and testing the new model) and evaluation of an adjusted model take place; and, through adjustment and enrichment, this new model is implemented. This is followed by reflection on the process and finally the consolidation of new practice and the extrapolation of this to generalization of this learning. (For a graphic representation, refer to Engeström \& Sannino, 2010, p. 7.) Dochy, Engeström, Sannino, and Van Meeuwen (2011) point out that this cycle is not unidirectional, but rather that movement occurs "back and forth between the different actions" (p. 138). Nor is this cycle immune from disruption, partial or complete. This questioning is embedded in effective tasks, and should be a central framework for any teacher engaged in TBLT. The explicit knowledge-making embedded in Expansive Learning Theory offers a framework for understanding TBLT pedagogy.This concept of cyclical learning is useful in understanding the learning experiences of foreign language learners as they grapple with the complexities of adjusting to the new cultural context of their target language. 
The initial point in the learning cycle of questioning is congruent with Schmidt's (1994) concept of noticing as an essential first step to language learning. The student becomes aware or notices a new language feature that they may want to assimilate into their language repertoire, but lacks the knowledge or skills to use this feature effectively. This would create a double bind or awareness of current knowledge limitation with desire to expand their repertoire. It is possible that, once experiencing the double bind, they will be more open to explore a range of strategies on a trial and error basis, selecting more effective strategies, discarding ineffective strategies, and building on or generalizing from the strategies that work. Implementing and analyzing these strategies will also increase learning, including knowledge of a grammatical form.

Defining task in TBLT has been the subject of much debate by both proponents and critics of the pedagogy. Nunan (2004) offers his own definition:

[A] pedagogic task is a piece of classroom work that involves the learner in comprehending, manipulating, producing or interacting in the target language while their attention is focused on mobilizing their grammatical knowledge in order to express meaning, and in which the intention is to convey meaning rather than to manipulate form. The task should also have a sense of completeness, being able to stand alone as a communicative act in its own right with a beginning, middle and an end. (p. 4)

Within this definition are key elements of meaning-making, and the expression of that meaning through grammatical knowledge, in tasks that engage learners in a range of thinking orders that expand their existing knowledge. The negotiation of meaning in both speaking and listening has been deemed central to comprehension and language acquisition (Pica, Holliday, Lewis, \& Morgenthaler, 1989). Through functional interactions in task-based learning environments, learners internalize their knowledge, which enables them to perform this knowledge independently. "Learning involves a progression from the inter- to intra-mental as learners shift from object and other regulation to self-regulation" (Ellis, 2003, p. 24). Learning through tasks is seen to transition through phases with an initial trigger, signal, response and follow-up (Pica, Holliday, Lewis, Berducci, \& Newman, 1991), as meaning is negotiated. Building on the theoretical construct of Comprehensible Output, Pica et al. (1989) developed a framework for the negotiation of meaning. A trigger is a communication that is not clearly understood by an interlocutor, giving rise to a signal which is an indication of noncomprehension. The response is clarification to aid comprehension, and follow-up closes the sequence, after meaning has been achieved. Many of these mini cycles can be embedded in larger task-based learning cycles. Negotiation of meaning as a transformational learning cycle is common to 
both TBLT pedagogy and Expansive Learning Theory, allowing students to engage in greater learning but also allowing teachers to design tasks that exploit this process.

These cyclical learning processes are demonstrated in Adjei-Barrett (2013). The students commence by addressing the tasks through questioning, analysis, formulating and testing potential solutions, making adjustments as a result of new information as a result of interactions, retesting and presenting these refined or updated solutions for class discussions, and finally consolidating new knowledge. As students wrestle with these comprehension tasks, there is evidence of a double bind, where prior knowledge or beliefs are deemed no longer appropriate, and "a corrective change in the system of sets of alternatives from which choice is made" (Bateson, 2000, p. 293). Initially reading, drawing on their existing vocabulary and grammar knowledge, and discussing with their peers, the students test a number of hypotheses. This is scaffolded by questions from the assistant teacher that prompt deeper exploration of the text. In the posttask phase, the teacher further questions the students, resulting in correct responses and allowing the students to exploit the new knowledge (Adjei-Barrett, 2013, pp. 104-108). In the limited excerpt from Adjei-Barrett, we can see the learning process as new vocabulary is acquired and used.

\section{Interacting Activity Systems}

In this section I discuss the various elements of interacting activity systems, demonstrate the congruence of TBLT as a subset of Expansive Learning Theory, and explain the benefits to TBLT pedagogy of this location. This elaboration focuses on each element, clarifying for ESL teachers how each element may contribute to strengthen task design and ensure robust language program development and implementation.

Activity Theory, evolving from Vygotsky $(1978)$ and Leont'ev $(1978,1981)$ conceptualized learning as an interaction of a number of elements (subject, mediating artefacts, rules, community, division of labour) mediated through the cultural context of the learning environment, creating an activity system. It is graphically represented as a triangle. By developing the concepts of Activity Theory through the introduction of a second triangle, "questions of diversity and dialogue between different traditions or perspectives" (Engeström, 2001, p. 135) are more easily elaborated. (For a graphic representation of the

two interacting activity systems as minimal model for the third-generation activity theory, Expansive Learning Theory, refer to Engeström, 2001, p. 136.) It is within the interacting activity systems that the pedagogy of TBLT is revealed. The diagram crystallizes the conception of the essential elements required for learning and the interactions between the elements, mediated through context, and the other activity system. Teachers represent a different perspective (engaged primarily with teaching) to the primary role of students, 
which is learning. The interaction between these two activity systems creates a common, shared artefact, which in TBLT is target language acquisition and use on a macro level, or on a micro level the accomplishment of learning from a single task (defined later in the article as Objects 3 and 2, respectively). An elaboration of these elements and interactions of the two activity systems, explaining their relevance to TBLT, follows.

Subject: Expansive Learning Theory regards the subject as person(s) engaged in the activity, and includes their motivation for that engagement and their will or desire to pursue that engagement. The subjects of TBLT pedagogy are the teacher(s) on the one hand and students on the other, each with their individual motivation for that engagement and the determination to pursue target language acquisition. As teachers, understanding their own motivation fuels the determination to refine and adapt teaching practices. Understanding the motivations of students allows teachers to design tasks to suit student needs, that is, to make teaching learner-centred.

Mediating artefacts: Evolving from Activity Theory, Expansive Learning Theory recognizes that learners mediate their learning through their cultural and historical knowledge-that is, personal history and prior knowledge are resources that learners use to interpret and address new information, which, through engagement in the activity, is modified to become knowledge. Self-aware teachers similarly draw on their prior knowledge and experience, and their teaching practices reflect their personal teaching styles. In TBLT, effective teachers design tasks that take into consideration the learning styles, interests, and prior knowledge of their students (Adjei-Barrett, 2013). TBLT is a learner-centred pedagogy, and placing TBLT within Expansive Learning Theory makes explicit the importance of cultural knowledge, personal history, and prior knowledge for task design, scaffolding learning, and language acquisition evaluation. It also positions Intercultural Communicative Competence (ICC) as a feature of both Expansive Learning Theory and TBLT; this will be discussed in detail in a following section.

Rules: All activities have pertinent rules, formal or informal, that determine or constrain learning. Knowledge of these rules is used to inform decisions related to the activity. Rules govern teachers, teaching, the subject being taught, and the way a task is structured, and they underpin acceptable class behaviour. In target language learning, knowledge of grammatical rules (form) plays a key role in the negotiation of meaning. Pica (2005) highlights the importance of designing tasks with clear goals that focus on the negotiation of meaning and that utilize knowledge of and the development of knowledge of grammatical rules, where "form, function, and meaning relationships [are] essential to task implementation and completion" (p. 345). More recent work (Ellis, 2009; Willis \& Willis, 2012) has clarified the centrality of focus on form through the completion of the three phases of TBLT. TBLT pedagogy is strengthened by its explicit acknowledgement of the place of knowledge of rules in language learning, 
further addressing the misconceptions that grammatical knowledge and accuracy are peripheral to the pedagogy.

Community, or "community of practice" with a shared "domain of knowledge, which defines a set of issues; a community of people who care about this domain; and the shared practice that they are developing to be effective in their domain" (Wenger, McDermott, \& Snyder, 2002, p. 27): Expansive Learning Theory recognizes that socially constructed learning is multivoiced. We learn from and with others through interaction. TBLT pedagogy is similarly premised, with interaction designed into tasks. Teachers draw on colleagues, co-teachers, researchers, and resource materials made available by those within this community. Students interact within the classroom with classmates, resource material, and teachers, learning from and with this community of practice.

Division of labour refers to those members of the community of practice who formally or informally undertake different roles during the course of the activity, working in concert to achieve a shared outcome. Within the community of practice of TBLT teachers, different roles are discernible-from resource development to sharing of professional discussion to co-teaching. Within classes, students participate with degrees of engagement-from leaders who are more vocal than others to those more passive in their engagement. In pair and group work that is often associated with TBLT, the division of labour may be seen with particular aspects of the task, sometimes with group leaders, scribes, those who check references, or those who report to the class. Explicit recognition of community of practice and division of labour in achieving expansive learning supports both task design and task delivery.

Context: Interactions between the elements are mediated through the context of the activity, with its specific culture and history. Interactions in TBLT are mediated through the curriculum framework, school policies, and school and classroom contexts. Teaching practices that recognize and address all elements necessary for expansive learning will be learner-centred, socially constructed learning environments that incorporate knowledge of language rules (form) as fundamental to the negotiation of meaning, mirroring TBLT pedagogy.

Object 1 is "unreflected, situationally given 'raw material'" (Engeström, 2001, p. 136) or, in the case of TBLT, the task that is the focus of the activity (target language acquisition and use) designed or adapted and delivered by the teacher, or the focus of the pretask phase.

Object 2 is "a collectively meaningful object constructed by the activity system" (Engeström, 2001, p. 136) or task phase of TBLT, where students produce a considered, negotiated outcome in preparation for the posttask phase. In the process of negotiating meaning, students draw on all available elements through their context. The teacher scaffolds meaning making, drawing on elements from their activity system. 
Object 3 is the "collaboratively constructed understanding" (Engeström, 2001, p. 136) or shared artefact of the interacting activity systems. In TBLT this would be understood as the posttask phase, where teacher(s) and students reflect on task performance, focus on form and accuracy, and refine and consolidate new knowledge.

In recognizing the congruence of Objects 1, 2, and 3 and pretask, task, and posttask phases, teachers can design and deliver task-based learning with greater purposefulness. The elaboration of TBLT as Expansive Learning Theory recognizes the multiple and complex roles of teachers in task design, scaffolding of learning, knowledge consolidation, and language acquisition evaluation. Adjei-Barrett (2013) elaborates on the role of the teacher that involves

the selection and preparation of materials for task models, and provides clear instructions, assessment and observation of language utilized in accomplishing the task, monitoring student interaction during task discussion, providing social and/or linguistic scaffolding to groups on an as needed basis, serves as facilitator rather than information-feeder. (p. 25)

During the posttask or language focus phase, Adjei-Barrett carefully guides and supports a focus on form, using skillful questioning that allows her to consolidate and evaluate students' learning. If this sequence is underpinned by an understanding of learning cycles, then teaching practices are clearly focused on learning through the negotiation of meaning, utilizing the collective resources elaborated in the elements of activity systems, with knowledge constructed and consolidated through social interaction.

\section{Intercultural Communication Competence}

TBLT has been criticized for its "relative silence" (East, 2012, p. 135) on Intercultural Communication Competence (ICC), but it has been noted as implicitly central to TBLT (East, 2012). TBLT's focus on meaning making and learning communication appropriacy binds together language knowledge and cultural knowledge, placing the meaning of the language within its cultural context. By placing TBLT within Expansive Learning Theory, ICC becomes explicitly a core element as students attempt to make meaning of a new language with a new cultural context. As Liddicoat (2008) points out, "Every message a human being communicates through language is communicated in a cultural context. Cultures shape the ways language is structured and the ways in which language is used" (p. 278). Culture and language are inseparable, and the central importance of meaning making in TBLT is positioned to exploit fully this relationship. In taking up the challenge of developing an appreciation of this relationship, East (2012) refers to the earlier work of Byram $(1997,2009)$ and Byram 
and Zarate (1996). Byram (1997) describes the factors in intercultural communication competence in a model, elaborating in detail each of his savoirs. Byram places great importance on discovery, interpretation, and establishing a relationship (1997, p. 48) in communicative competence and redefines linguistic competence, sociolinguistic competence, and discourse competence to reflect these key aspects. Byram sees these aspects as implicit in the skills and knowledge factors. Byram's inclusion of "critical cultural awareness" and the "knowledge of self and other, of interaction both individual and societal" (1997, p. 48), along with attitudes of "relativising self and valuing others," draws together the important understanding that students use their own cultural knowledge and history as a resource for learning. This personal knowledge is modified by interaction during the course of foreign language learning.

Liddicoat and Scarino (2013) make this connection succinctly:

Participants in communication bring to it their own linguistic and cultural biographies, their distinctive frames of reference that come from their history and prior experiences, their meanings, and values. In the act of communicating, they engage in mutual interpretation to negotiate their own meanings in relation to those of others. (pp. 43-44)

It is the "moving between" the linguistic and cultural systems (Liddicoat \& Scarino, 2013, p. 43) that creates the tensions and modifications to sets of beliefs that move the learner through the double bind to new and transformative knowledge. Expansive Learning Theory, premised on interaction and the importance of learner culture and history as a mediational artefact as learners make sense of new information, accords well with TBLT. TBLT would be strengthened by the recognition that learning is enabled through the mediation of the individual's cultural and historical background. Liddicoat and Scarino (2013) argue persuasively for the inclusion of these dimensions of "task":

1. to highlight the nature of interaction as the reciprocal interpretation and creation of meaning

2. to acknowledge that for learners these interactions constitute experiences along an evolving understanding of what it is that communication entails, and ultimately, the learners' development of self-awareness as communicators. (p. 63)

Much of this is implicit in the learner-centredness of pedagogies such as TBLT that develop the curriculum with the attributes of the learners in focus, and task design that requires interaction between the learner, the learning material, and other class participants as learners negotiate meaning. Parks (2000) argues strongly for "task-based research that takes into account the sociocultural dimension of task performance and learner's 
perspective" (p. 64). She underscores the importance of motivation and the subsequent choices of strategies employed to achieve the learning outcomes of the participants, and the mediation of personal culture and history that privileges "the appropriation of, or resistance to, particular strategies" ( $p$. 64). The deliberate exploitation of students' personal culture and history, both as a resource for learning and also as an integral part of the content learning involved in foreign language acquisition, is common to Expansive Learning Theory and TBLT.

The connections between TBLT and sociocultural theories of learning are not new (Adjei-Barrett, 2013; East, 2012; Ellis, 2003, 2009; Liddicoat, 2008; Liddicoat \& Scarino, 2013). Nor is the connection between intercultural interaction competence and target language acquisition revelatory (Byram, 1997, 2009; Byram \& Zarate, 1996; East, 2012; Liddicoat, 2008; Liddicoat \& Scarino, 2013), nor indeed between TBLT specifically and ICC (East, 2012; Liddicoat \& Scarino, 2013). However, situating TBLT pedagogy within Expansive Learning Theory would appear to be arguably sound. There is a remarkable synergy between learning conceptualization in both TBLT and Expansive Learning Theory. The placement of language rules (knowledge of grammar) as an essential element to negotiation of meaning, along with elements of culture and history as mediational artefacts, that both contributes to and shapes or scaffolds learning that presumes intercultural knowledge development strengthens TBLT as a pedagogy. In placing TBLT pedagogy within the theoretical frame of Expansive Learning Theory learning processes, the elements of the activity system become available to support teachers in the design of effective tasks and their teaching practices, and in teacher training and professional development. Further research may develop this conceptualization and make a valuable contribution to the development of TBLT and to language teaching generally.

\section{The Author}

Margaret Robertson is a doctoral student at LaTrobe University, Australia. Her interest in pedagogy has developed from a long career in primary and secondary education in Australia and China where she taught students from bilingual kindergartens and offered corporate training for multinational companies. What is taught, why, and how is a rich field for understanding and ultimately improving learning outcomes.

\section{References}

Adjei-Barrett, A. (2013). Task-based interactions in Spanish as a foreign language classroom (Doctoral dissertation). Retrieved from ProQuest. (Publication No. 3565710)

Alexander, R. (2013). Essays on pedagogy. Hoboken, NJ: Taylor and Francis.

Bateson, G. (2000). Steps to an ecology of mind. Chicago, IL: University of Chicago Press.

Bruton, A. (2002). From tasking purposes to purposing tasks. ELT Journal, 56(3), 280-288.

Byram, M. (1997). Teaching and assessing intercultural communicative competence. Clevedon, UK: Multilingual Matters.

Byram, M. (2009). Intercultural competence in foreign languages. In D. K. Deardorff (Ed.), The Sage handbook of intercultural competence (pp. 321-332). Thousand Oaks, CA: Sage. 
Byram, M., \& Zarate, G. (1996). Defining and assessing intercultural competence: Some principles and proposals for the European context. Language Teaching, 29(4), 239-243.

Dochy, F., Engeström, Y., Sannino, A., \& Van Meeuwen, N. (2011). Inter-organisational expansive learning at work. In F. Dochy, D. Gijbels, M. Segers, \& P. Van den Bossche (Eds.), Theories of learning for the workplace (pp. 125-147). New York, NY: Routledge.

East, M. (2012). Task-based language teaching from the teachers' perspective: Insights from New Zealand. Amsterdam, The Netherlands: John Benjamins.

Ellis, R. (2003). Task-based language learning and teaching. Oxford, UK: Oxford University Press.

Ellis, R. (2009). Task-based language teaching: Sorting out the misunderstandings. International Journal of Applied Linguistics, 19(3), 221-246.

Engeström, Y. (2001). Expansive learning at work: Toward an activity theoretical reconceptualization. Journal of Education and Work, 14(1), 133-156.

Engeström, Y., \& Sannino, A. (2010). Studies of expansive learning: Foundations, findings and future challenges. Educational Research Review, 5(1), 1-24.

Hampshire, S., \& Aguareles Anoro, M. A. (2004). The siren call of the task. ELT Journal, 58(1), 71-74.

Leont'ev, A. N. (1978). Activity, consciousness, and personality. Englewood Cliffs, NJ: Prentice-Hall.

Leont'ev, A. N. (1981). Problems of the development of the mind. Moscow, Russia: Progress Publishers.

Liddicoat, A. J. (2008). Pedagogical practice for integrating the intercultural in language teaching and learning. Japanese Studies, 28(3), 277-290.

Liddicoat, A. J., \& Scarino, A. (2013). Intercultural language teaching and learning. Chichester, UK: Wiley.

MacNeill, N., \& Silcox, S. (2003). Pedagogic leadership: Putting professional agency back into learning and teaching. Curriculum \& Leadership Journal. Retrieved from http://www.curriculum. edu.au/leader/default.asp?issueID=9691\&id $=4625$

Nunan, D. (2004). Task-based language teaching. Cambridge, UK: Cambridge University Press.

Parks, S. (2000). Same task, different activities: Issues of investment, identity, and use of strategy. TESL Canada Journal, 17(2), 64-88.

Pica, T. (2005). Classroom learning, teaching, and research: A task-based perspective. Modern Language Journal, 89(3), 339-352.

Pica, T., Holliday, L., Lewis, N., Berducci, D., \& Newman, J. (1991). Language learning through interaction: What role does gender play? Studies in Second Language Acquisition, 13(3), 343376.

Pica, T., Holliday, L., Lewis, N., \& Morgenthaler, L. (1989). Comprehensible output as an outcome of linguistic demands on the learner. Studies in Second Language Acquisition, 11(1), 63-90.

Prabhu, N. S. (1987). Second language pedagogy. Oxford, UK: Oxford University Press.

Schmidt, R. (1994). Deconstructing consciousness in search of useful definitions for applied linguistics. AILA Review, 11, 11-26.

Seedhouse, P., Walsh, S., \& Jenks, C. (2010). Conceptualising 'learning' in applied linguistics. Basingstoke, UK: Palgrave Macmillan.

Sheen, R. (2003). Focus on form: A myth in the making? ELT Journal, 57(3), 225-233.

Swan, M. (2005). Legislation by hypothesis: The case of task-based instruction. Applied Linguistics, 26(3), 376-401.

Vygotsky, L. S. (1978). Mind in society. Cambridge, MA: Harvard University Press.

Wenger, E., McDermott, R., \& Snyder, W. M. (2002). Cultivating communities of practice: A guide to managing knowledge. Boston, MA: Harvard Business School Press.

Willis, D., \& Willis, J. (2012). Doing task-based teaching. Oxford, UK: Oxford University Press. (Original work published 2007) 